\title{
Investigating in Vitro Amyloid Peptide 1-42 Aggregation: Impact of Higher Molecular Weight Stable Adducts
}

\author{
Angela De Simone, ${ }^{\dagger}$ Marina Naldi, ${ }^{\ddagger, \S}$ Daniele Tedesco, ${ }^{\ddagger}$ Andrea Milelli, ${ }^{\dagger}$ Manuela Bartolini, \\ Lara Davani, ${ }^{\dagger}$ Darius Widera," Mark L. Dallas," and Vincenza Andrisano* ${ }^{* \dagger}$ \\ ${ }^{\dagger}$ Department for Life Quality Studies, Alma Mater Studiorum Università di Bologna, Rimini 47921, Italy \\ ${ }^{\ddagger}$ Department of Pharmacy and Biotechnology, Alma Mater Studiorum Università di Bologna, Bologna 40126, Italy \\ ${ }^{\S}$ Center for Applied Biomedical Research (C.R.B.A.) S. Orsola-Malpighi Hospital, Bologna 40126, Italy \\ "Reading School of Pharmacy, University of Reading, Reading RG6 6UB, U.K.
}

\section{Supporting Information}

ABSTRACT: The self-assembly of amyloid peptides $(\mathrm{A} \beta)$, in particular $\mathrm{A} \beta_{1-42}$, into oligomers and fibrils is one of the main pathological events related to Alzheimer's disease. Recent studies have demonstrated the ability of carbon monoxide-releasing molecules (CORMs) to protect neurons and astrocytes from $\mathrm{A} \beta_{1-42}$ toxicity. In fact, CORMs are able to carry and release controlled levels of $\mathrm{CO}$ and are known to exert a wide range of anti-inflammatory and anti-apoptotic activities at physiologically relevant concentrations. In order to investigate the direct effects of CORMs on $\mathrm{A} \beta_{1-42}$, we studied the reactivity of CORM-2 and CORM-3 with $\mathrm{A} \beta_{1-42}$ in vitro and the potential inhibition of its aggregation by mass spectrometry (MS), as well as fluorescence and circular dichroism spectroscopies. The application of an electrospray ionization-MS (ESIMS) method allowed the detection of stable $\mathrm{A} \beta_{1-42} / \mathrm{CORMs}$ adducts,

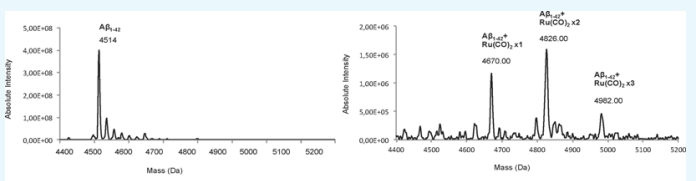
involving the addition of the $\mathrm{Ru}(\mathrm{CO})_{2}$ portion of CORMs at histidine residues on the $\mathrm{A} \beta_{1-42}$ skeleton. Moreover, CORMs showed anti-aggregating properties through formation of stable adducts with $\mathrm{A} \beta_{1-42}$ as demonstrated by a thioflavin $\mathrm{T}$ fluorescence assay and MS analysis. As further proof, comparison of the $\mathrm{CD}$ spectra of $\mathrm{A} \beta_{1-42}$ recorded in the absence and in the presence of CORM-3 at a 1:1 molar ratio showed the ability of CORM-3 to stabilize the peptide in its soluble, unordered conformation, thereby preventing its misfolding and aggregation. This multimethodological investigation revealed novel interactions between $\mathrm{A} \beta_{1-42}$ and CORMs, contributing new insights into the proposed neuroprotective mechanisms mediated by CORMs and disclosing a new strategy to divert amyloid aggregation and toxicity.

\section{INTRODUCTION}

The aggregated forms of amyloid beta peptide $(\mathrm{A} \beta)$ have a significant correlation with a growing number of diseases, including but not limited to neurodegeneration. ${ }^{1}$ Indeed, the assembly of misfolded amyloid peptides into cytotoxic oligomeric and $\beta$-sheet-rich fibrillar aggregates ${ }^{2}$ is one of the major pathological events that occur in the progression of Alzheimer's disease $(\mathrm{AD})^{3,4}$ The synaptotoxicity of $\mathrm{A} \beta$ oligomers, $^{5-8}$ along with their neurotoxicity and proinflammatory effects of $\mathrm{A} \beta$ fibrils ${ }^{9}$ make targeting $\mathrm{A} \beta$ assembly an interesting therapeutic approach to treat $\mathrm{AD} .{ }^{10}$ The effects of $\mathrm{A} \beta \mathrm{s}$ are not restricted to neurons as increasing evidence indicates a modulation of glia physiology. ${ }^{11-13}$ It has been reported that deposition of $\mathrm{A} \beta \mathrm{s}$ leads to an impairment of astrocytic function ${ }^{14}$ and that astrocytes may undergo atrophy and degeneration at the early stages of disease progression in animal models of $\mathrm{AD}$ as a result of $\mathrm{A} \beta$ exposure. ${ }^{15,16}$ Because of their fundamental role in ionic homoeostasis and cell regeneration, astrocyte dysfunction contributes to brain aging and neurodegeneration. Recently, the use of endogenous molecules to protect neurons from $\mathrm{A} \beta_{1-42}$ toxicity by modulation of neuronal or glia processes has been explored. Carbon monoxide ( $\mathrm{CO}$ ) is a well-established gaseous toxic molecule. ${ }^{17}$ Exposure to elevated levels of environmental $\mathrm{CO}$ is suggested to promote cognitive decline. ${ }^{18}$ However, recently, $\mathrm{CO}$ has received growing attention due to its ability to modulate an array of cell signaling cascades pertinent to neurodegeneration. ${ }^{19-23}$ These studies have used a wide array of reagents to investigate the role for CO: (1) heme oxygenase1 induction; (2) CO releasing molecules (CORMs); or (3) exposure to $\mathrm{CO}$ gas, highlighting a distinct role for both endogenous and exogenous $\mathrm{CO}$. These studies have demonstrated the ability of CORMs to protect both neurons and astrocytes from $\mathrm{A} \beta_{1-42}$ toxicity in vitro ${ }^{22,23}$ and have

Received: May 24, 2019

Accepted: July 5, 2019

Published: July 18, 2019 
highlighted distinct cellular pathways involved in the cytoprotective effects of CORMs. For example, exposure of astrocytes to $\mathrm{CO}$ has been reported to result in a reduction of $\mathrm{A} \beta_{1-42}$ toxicity via inhibition of $\mathrm{NADPH}$ oxidase-derived reactive oxygen species (ROS) production. In contrast, neuronal protection was facilitated by $\mathrm{CO}$ suppression of AMP-activated kinase mediated by $\mathrm{A} \beta_{1-42}{ }^{24}$ Based on these studies and other reports, ${ }^{25,26}$ the opportunity of preventing amyloid-induced cellular degeneration through the use of $\mathrm{CO}$ donors or heme oxygenase-1 (HO-1) induction ${ }^{22,23}$ deserves further investigation. ${ }^{27}$ In this context, the present work also aimed at assessing additional mechanisms responsible for the reported CORM-mediated reduction of amyloid toxicity in living cells. ${ }^{22,23}$ The use of CORMs such as CORM-2 and CORM-3 (Figure 1) precisely suits this purpose. CORMs have

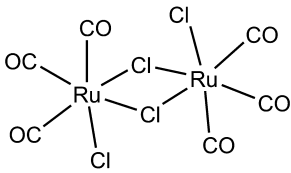

CORM-2

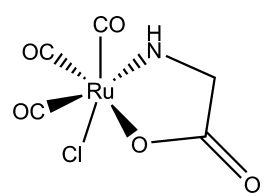

CORM-3
Figure 1. CORM structures. Chemical structures of two widely used CORM molecules, CORM-2 and CORM-3.

been proposed as pharmaceutical agents by Motterlini, Mann, and co-workers in 2002. ${ }^{28}$ Since then, the transition metal carbonyls, in particular CORM-3 and CORM-2, have been studied in detail. ${ }^{29}$ The biological and therapeutic activity of these compounds have been largely assessed by in vitro, ex vivo, and in vivo studies. ${ }^{30,31}$ Moreover, the water solubility and stability in air of CORM-3 make it more suitable for therapeutic use. Previous studies have indicated that CORM3 has therapeutic benefits in several animal models for a series of diseases, including rheumatoid arthritis and myocardial infarction. $^{32,33}$ These studies also revealed an important clinical feature of CORM-3; at therapeutic doses, no increase of $\mathrm{COHb}$ (CO Hemoglobin) blood levels was detected. Starting from these bases, other studies have been conducted in order to explain the mechanism for the release of $\mathrm{CO}$ by CORMs. ${ }^{34-38}$

In addition, there is a growing body of evidence indicating the interaction of CORMs with distinct protein substrates. $^{39-41}$ In particular, Santos-Silva and co-workers reported a rapid formation of stable adducts between the His 15 residue of lysozyme and the cis- $\mathrm{Ru}(\mathrm{CO})_{2}$ fragment of CORM-3 as the result of the chloride ion, glycinate, and one CO loss (Figure 2). ${ }^{35}$ Silvas et al. demonstrated, by electrospray ionization-MS (ESI-MS) studies, that the $\mathrm{Ru}$ carbonyl fragments of a $\left[\mathrm{Ru}(\mathrm{CO})_{3} \mathrm{Cl}_{2}(1,3\right.$-thiazole $\left.)\right]$ species bind to the His 15 residue of lysozyme. ${ }^{42}$ The same reactivity was also demonstrated for some Ru-based CORMs with azole ligands. ${ }^{40}$ In both cases, data obtained by ESI-MS experiments were confirmed by crystallographic studies. The collected evidence revealed the tendency of $\mathrm{Ru}$ fragments to interact with the $\mathrm{N} \varepsilon 2$ of His15 of lysozyme. Additional binding sites have been reported to be close to Asp and Arg residues. ${ }^{40,42}$ The same reactivity was also reported for the Ru complex fac$\left[\mathrm{Ru}(\mathrm{CO})_{3}\left(\mathrm{Cl}_{2}-\mathrm{N}^{1}-\right.\right.$ thz $\left.)\right]$ and $\mathrm{A} \beta$ peptide $1-28$. Valensin et al. highlighted by $1 \mathrm{D}$ NMR the interaction of this complex with the three His residues located in the $\mathrm{N}$-terminal domain of $\mathrm{A} \beta$ peptide. $^{43}$

What makes the study of CORMs interaction with $\mathrm{A} \beta$ and the investigation of CORM anti-aggregating properties even more intriguing is the presence of a metal cation in their structure. Indeed, since the discovery and application of the most relevant platinum(II) complex, cis- $\left[\mathrm{Pt}\left(\mathrm{NH}_{3}\right)_{2} \mathrm{Cl}_{2}\right]$, also known as cisplatin, ${ }^{44,45}$ the development of metal complexes addressed to different diseases including neurodegenerative disorders, cancer, diabetes, inflammation, and cardiovascular disease has significantly increased. ${ }^{46-48}$ From an $\mathrm{AD}$ perspective, the interest in $\mathrm{A} \beta$-targeted metal complexes as anti-AD agents has increased over the past two decades. ${ }^{49-51}$ This is due to their appealing physiochemical properties and is based on the finding that the amyloid plaques in $\mathrm{AD}$ patients are enriched in transition-metal cations such as $\mathrm{Cu}, \mathrm{Fe}$, and $\mathrm{Zn}^{52-55}$ The finding that the dyshomeostasis of such metal ions is correlated with $\mathrm{AD}^{56-58}$ led to the metal ion hypothesis. $^{59,60}$ Indeed, these cations possess a high binding affinity for $\mathrm{A} \beta$ and their ability to mediate the aggregation process in vitro has been assessed. ${ }^{57,61,62}$ Moreover, they are also implicated in the production of ROS induced by A $\beta .^{63,64}$ Many metal complexes have been used in $\mathrm{AD}$ as therapeutic, diagnostic, and theranostic agents. The strategies adopted for transition-metal complexes toward modulation of $\mathrm{A} \beta$ aggregation are different. Among them, the coordination, oxidation, and hydrolysis of $\mathrm{A} \beta$ are the most common. ${ }^{65,66}$ The first metal complexes with anti-aggregating properties were reported by Barnham and co-workers in 2008. ${ }^{50}$ They demonstrated that $\mathrm{Pt}^{2+}-1$, 10-phenantroline complexes interacted with the $\mathrm{N}$ terminal domain. The binding of $\mathrm{Pt}^{2+}$ to $\mathrm{N}$-terminal histidine residues was shown. This formation of the coordination adduct was able to influence the behavior of the $\mathrm{A} \beta$ peptide. Brewer and co-workers studied many complexes containing $\mathrm{Pt}^{2+}$ and $\mathrm{Ru}^{2+}$ metal centers. ${ }^{67-69}$ Because of their attractive biological features, ruthenium complexes are considered a valid alternative to platinum-based ones. ${ }^{65}$ More recently, Messori and co-workers presented a $\mathrm{Ru}^{2+}$ complex able to protect cortical neurons against $\mathrm{A} \beta_{1-42}$ toxicity in an in vitro model. ${ }^{49}$ However, it has been shown that most of these complexes possess a higher affinity for fibrils than for oligomers. The fact
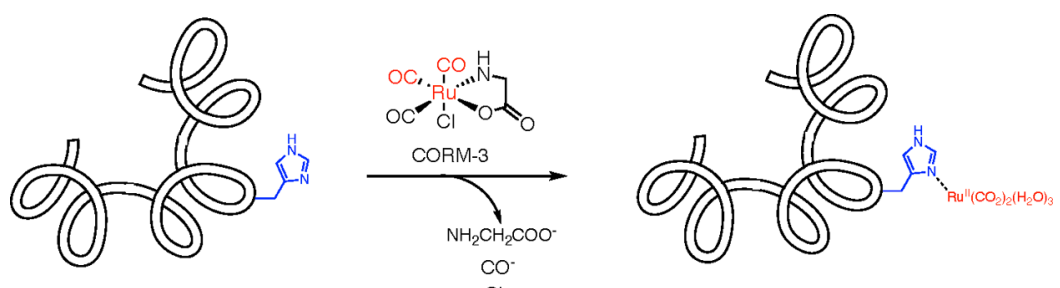

Figure 2. CORM-3 protein interactions. Interactions of CORM-3 with lysozyme result in the loss of a chloride ion, glycinate, and one CO ligand, leading to the rapid formation of stable adducts between the protein and the remaining $\mathrm{Ru}(\mathrm{CO})_{2}{ }^{35}$ 
that $\mathrm{A} \beta$ oligomers are the most toxic species pushes research toward the discovery of new complexes targeting these species. Based on these premises and to the awareness that one of the major strategies pursued for $\mathrm{AD}$ is focused on the stabilization of the $\mathrm{A} \beta$ monomer in its native non-amyloidogenic state, ${ }^{10,70,71}$ our aim was to explore the mechanism by which CORMs 3 and 2 (Figure 1), or carbon monoxide, directly react with $\mathrm{A} \beta_{1-42}$ and stabilize the peptide in its native form, impeding the amyloidogenic conformational transition and formation of toxic assemblies and fibrils. We have previously reported that oxidized $\mathrm{A} \beta_{25-35}$ peptide is less prone to aggregation. $^{72}$ The aggregation pathway was previously investigated by our group in an $\mathrm{A} \beta_{1-42}$ kinetic aggregation study carried out using a multi-methodological approach. ${ }^{73}$ Therefore, the ability of CO-releasing molecules to directly bind to $\mathrm{A} \beta_{1-42}$ and affect $\mathrm{A} \beta$ conformational transition and aggregation has been investigated here by mass spectrometry (MS), circular dichroism (CD) spectroscopy, and a thioflavin $\mathrm{T}$ (ThT)-based fluorescence assay.

Each technique provides information on the interaction of the $\mathrm{A} \beta$ amyloid peptide with metal complexes during the different phases of its aggregation. ${ }^{72-76}$ Liquid chromatograph-MS (LC-MS) experiments provided evidence for the formation of some stable noncovalent adducts between CORMs and plasma proteins. ${ }^{38}$ ESI-MS is indeed one of the most suitable techniques used to characterize complexes formed by metal compounds and proteins, ${ }^{77}$ in particular with the $\mathrm{A} \beta$ peptide. ${ }^{78-80}$ Consequently, the main question that we address in this work is if CORMs can show other functions in counteracting amyloid toxicity via a specific reactivity with amyloid in addition to the reported beneficial $\mathrm{CO}$ effects mediated by $\mathrm{HO}-1$. Additionally, we investigated if $\mathrm{CO}$ could react with $\mathrm{A} \beta_{1-42}$ in a similar fashion as oxygen.

\section{RESULTS AND DISCUSSION}

In order to study the CORMs/A $\beta_{1-42}$ interaction, we carried out a multi-methodological approach, which provides insights into the stabilizing and anti-aggregating properties of amyloid interacting molecules and allows elucidating their mechanism of action. As $\mathrm{A} \beta$ toxicity is related to specific prefibrillary species, ${ }^{81}$ it is important to follow the kinetics of the $\mathrm{A} \beta$ assembly. Many compounds are characterized in terms of interaction with fibrils but not with prefibrillary species. ${ }^{82}$ Therefore, this multi-methodological approach can give a more comprehensive view of the CORMs/A $\beta$ interaction. For example, the anti-aggregating properties of myricetin were shown by ThT-fluorescence assay, whereas its ability to prevent structural changes in $\mathrm{A} \beta_{1-42}$ was confirmed by $\mathrm{CD}$ studies. $^{73,74}$ Moreover, MS techniques allowed monitoring the modifications induced by myricetin on the monomer and the first occurring $\mathrm{A} \beta_{1-42}$ self-assembly species. ${ }^{75}$ In brief, persistent level of monomers and the decreased formation of ordered $\mathrm{A} \beta_{1-42}$ oligomeric aggregates in the presence of myricetin were shown. In addition, these studies highlighted the oxidation of the peptide at Met35 via formation of a sulfoxide that is less prone to aggregation with a concomitant loss of cytotoxicity and decrease in protein oxidation. ${ }^{75}$ Therefore, we applied a similar multi-methodological approach and used myricetin as a reference inhibitor. The choice of myricetin as the reference inhibitor is due to its proven antiaggregating properties. Moreover, its mechanism of action was well characterized by different studies based on MS and our multi-methodological approaches. $72,73,75,76$
2.1. Evaluation of $\mathrm{A} \beta_{1-42} / \mathrm{CORM}-3$ Interaction by $\mathrm{MS}$. Evidence of CORMs protective effects against $\mathrm{A} \beta_{1-42}$ toxicity in vitro and capacity to form stable adducts with histidine residues of different proteins ${ }^{35}$ prompted us to investigate their interaction with $\mathrm{A} \beta_{1-42}$ by $\mathrm{MS}$ analysis. Following the experimental procedure previously reported by Bartolini et al., ${ }^{74} \mathrm{~A} \beta_{1-42}$ was incubated at $30{ }^{\circ} \mathrm{C}$ for $3 \mathrm{~h}$ in the absence and in the presence of either CORM-2 or CORM-3 to achieve final $\mathrm{CORM} / \mathrm{A} \beta_{1-42}$ molar ratios (MRs) ranging from 0.1 to 10 to gain insights into the reaction of CORMs with the His residues of $\mathrm{A} \beta_{1-42}$.

In Figure $3 \mathrm{a}$, the characteristic multicharged mass spectrum of native $\mathrm{A} \beta_{1-42}$ is shown. The analysis of the ESI-MS spectra

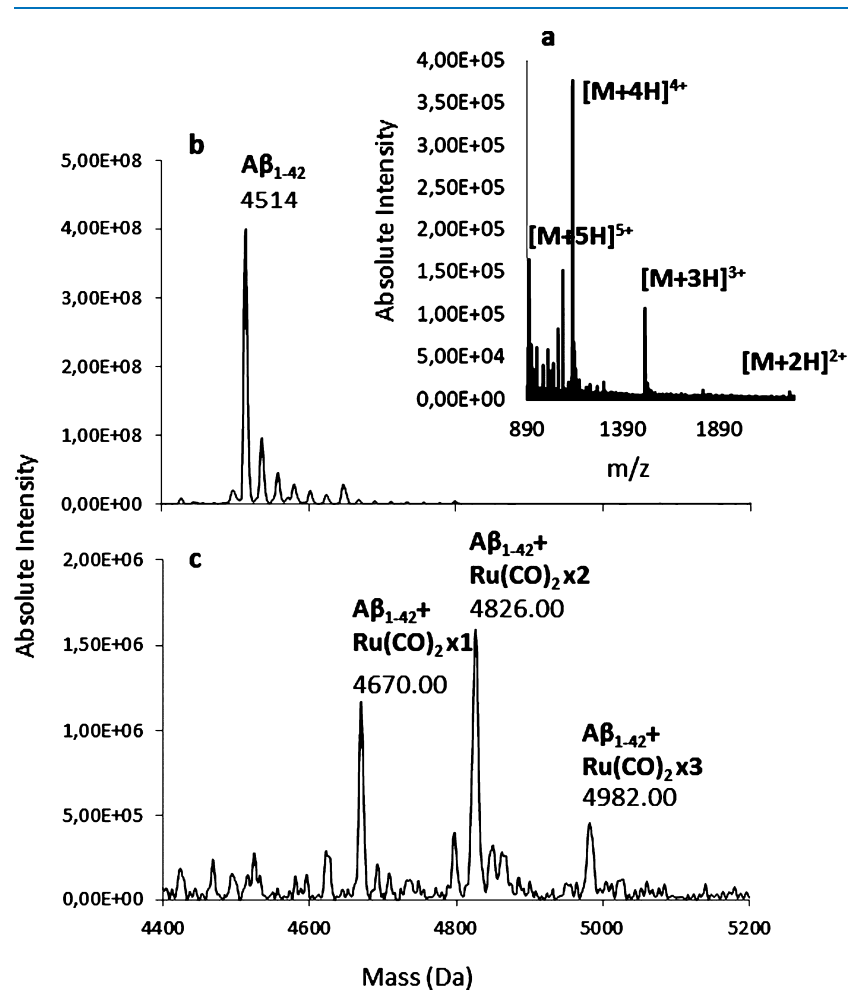

Figure 3. Mass spectra of $\mathrm{A} \beta_{1-42} / \mathrm{CORM}$ assemblies. (Upper panel) (a) $\mathrm{A} \beta_{1-42}$ multicharged mass spectrum and (b) $\mathrm{A} \beta_{1-42}$ deconvoluted mass spectrum. (Lower panel) (c) $\mathrm{A} \beta_{1-42}$ deconvoluted mass spectrum after its incubation with CORM-3 for $3 \mathrm{~h}$ at $30{ }^{\circ} \mathrm{C}$ (molar ratio CORM-3/A $\beta_{1-42}=10$ ).

exposed the generation of different charge states of the monomer. The resulting signals were attributed to $\mathrm{A} \beta_{1-42}$ charge states ranging from 2 to 5 ions, the most intense being $[\mathrm{M}+4 \mathrm{H}]^{4+}$ at $1129.3 \mathrm{~m} / z,[\mathrm{M}+5 \mathrm{H}]^{5+}$ at $903.7 \mathrm{~m} / z$, and $[\mathrm{M}$ $+6 \mathrm{H}]^{6+}$ at $753.3 \mathrm{~m} / \mathrm{z}$ (Figure $3 \mathrm{a}$ ). The deconvoluted MS spectrum of $\mathrm{A} \beta_{1-42}$, not treated with CORMs (Figure $3 \mathrm{~b}$ ) shows an intense signal at $4514 \mathrm{Da}$, which corresponds to the molecular weight of the native form of the peptide. However, when $\mathrm{A} \beta_{1-42}$ was incubated with CORM-3 at higher concentration $\left(\mathrm{CORM}-3 / \mathrm{A} \beta_{1-42}=10\right)$, new species at higher molecular weights were detected (Figure $3 \mathrm{c}$ ). The deconvoluted mass spectra revealed the addition of $\mathrm{Ru}(\mathrm{CO})_{2}$ to $\mathrm{A} \beta_{1-42}$. In particular, a mass increment of $156 \mathrm{Da}$ for the interaction of $\mathrm{Ru}(\mathrm{CO})_{2}$ to each His residue was detectable, producing signals at 4670,4826 , and $4982 \mathrm{Da}$, related to the addition of 1,2 , and $3 \mathrm{Ru}(\mathrm{CO})_{2}$ moieties, respectively. These species derive from the formation of stable adducts between $\mathrm{A} \beta_{1-42}$ and $1-3$ 
$\mathrm{Ru}(\mathrm{CO})_{2}$ groups from CORM-3 (molecular weight of 156 $\mathrm{Da})$. As the primary sequence of $\mathrm{A} \beta_{1-42}$ contains three histidine residues and CORMs are known to form stable adducts with this amino acid, ${ }^{35}$ the $\mathrm{A} \beta_{1-42} / \mathrm{CORMs}$ reaction may reasonably occur at this level (Figure 2). The extent of $\mathrm{A} \beta_{1-42} / \mathrm{CORMs}$ adducts formation was found to be proportional to CORM concentrations. Indeed, increased mono-, di-, and tri-modified forms of the peptide (Figure $4 \mathrm{~b}, \mathrm{c}$ ) were detected at increasing CORM-2 and CORM-3 concentration. Indeed, compared to CORM-3, the disappearance of the native

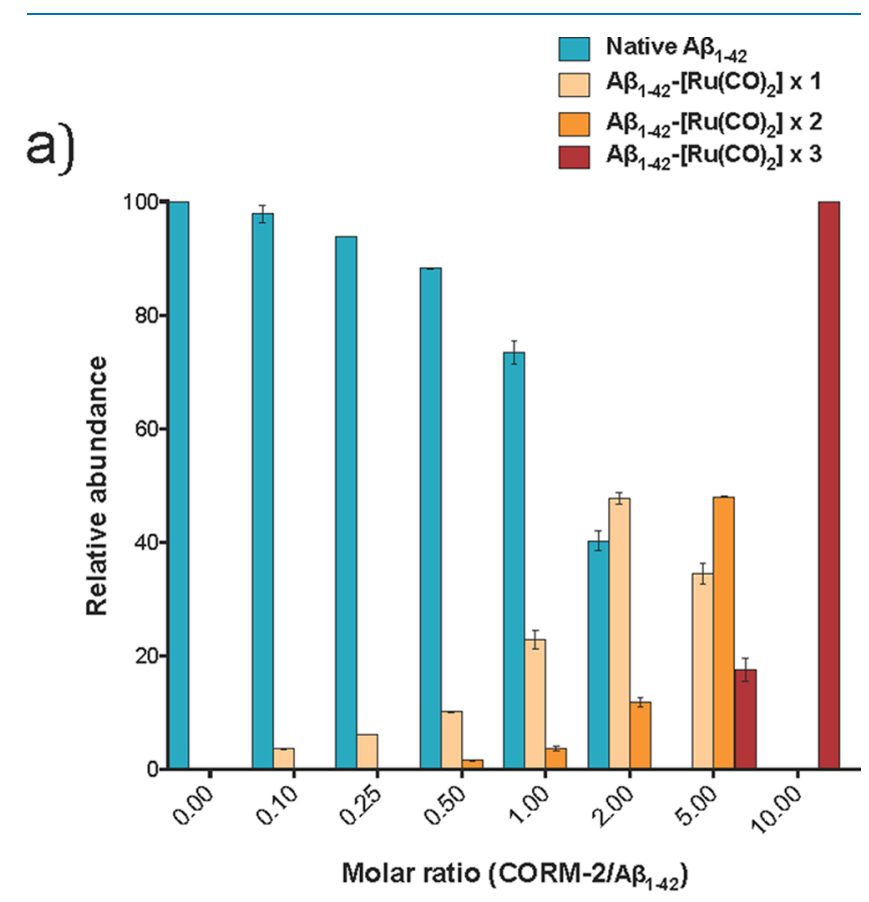

b)

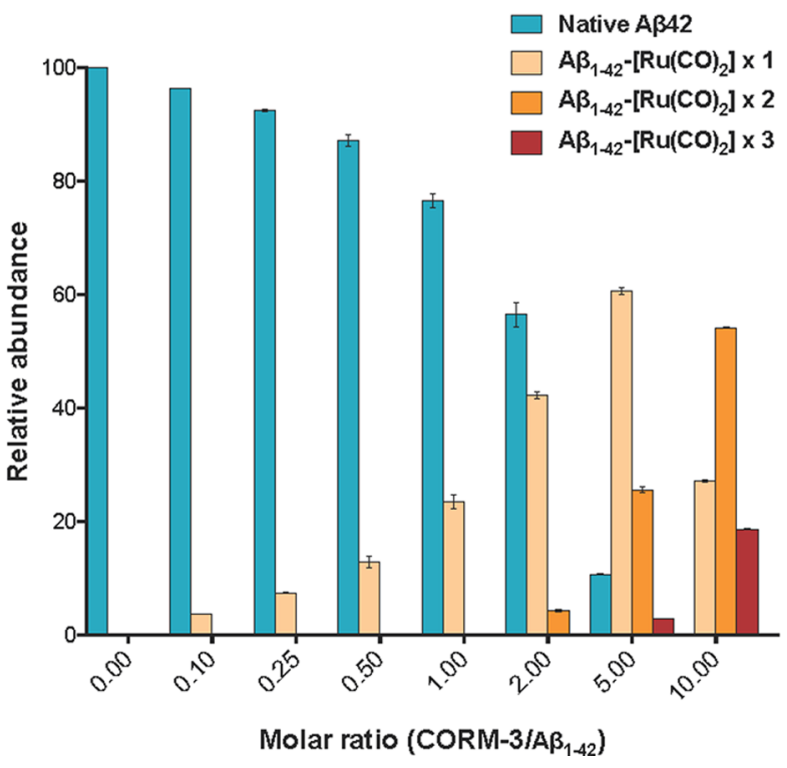

Figure 4. CORMs $/ \mathrm{A} \beta_{1-42}$ adducts abundance as a function of CORMs $/ \mathrm{A} \beta_{1-42}$ molar ratio. The relative abundance of $\mathrm{A} \beta_{1-42}$ species as a function of CORM-2 or CORM-3/A $\beta_{1-42}$ molar ratio is reported in panels $\mathrm{a}$ and $\mathrm{b}$, respectively. $\mathrm{A} \beta_{1-42}(50 \mu \mathrm{M})$ and CORMs at different concentrations $(0-500 \mu \mathrm{M})$ were incubated at $30{ }^{\circ} \mathrm{C}$ for $3 \mathrm{~h}$ and analyzed by ESI-MS. The $\mathrm{A} \beta_{1-42}$ species relative abundances were derived from the deconvoluted ESI-MS spectrum. form of $\mathrm{A} \beta_{1-42}$ required a lower CORM-2 concentration (MR $=5$ instead of 10; Figure 4b,c). At low CORM molar ratio, only the mono modified form of $\mathrm{A} \beta_{1-42}$ is evident, with the native $\mathrm{A} \beta_{1-42}$ peptide concomitantly being transformed. By increasing the $\mathrm{CORM} / \mathrm{A} \beta_{1-42}$ molar ratio, peptide modification was more pronounced, with the modification of the monohistidine-modified form into bis- histidine- and trishistidine-modified $\mathrm{A} \beta_{1-42}$ adducts (Figure 4). In particular, CORM-2 induced a complete disappearance of the native $\mathrm{A} \beta_{1-42}$ form and the concomitant formation of $\mathrm{A} \beta_{1-42^{-}}$ modified forms in which two or three histidine residues are modified. This higher reactivity of CORM-2 can be explained by the fact that two ruthenium moieties are present in the CORM-2 structure, whereas CORM-3 bears only one.

2.2. Identification of $A \beta_{1-42}$ Amino Acids Involved in the Formation of Stable Adducts with CORM-3 and CORM-2. A bottom-up approach was employed to assess the $\mathrm{A} \beta_{1-42}$ amino acidic residues involved in the formation of stable adducts with CORM-2 and 3. A $\beta_{1-42}$ was incubated for $3 \mathrm{~h}$ at $30{ }^{\circ} \mathrm{C}$ in the absence and in the presence of CORMs at final CORM $/ \mathrm{A} \beta_{1-42}$ molar ratio of 5 or 10 before digestion with trypsin. Peptides from the tryptic digestion of untreated $\mathrm{A} \beta_{1-42}$ were all identified (Figure 1 , Supporting Information). Analysis of the tryptic digests, resulting from incubation with CORMs, highlighted modification only at peptide 6-16, independently from the type of CORM and molar ratio. In particular, the mono-modified form of the peptide $6-16$ (as dicharged form $-m / z=747.5$ ) was detected after incubation with CORM-3 at molar ratio equal to 5 (Figure 2, Supporting Information). The identity of the adduct was confirmed by the characteristic ruthenium isotope pattern, which perfectly matched that previously reported by Hong and co-workers. ${ }^{83}$ MS/MS analysis of this peptide allowed final identification of residue His6 as the amino acid residue involved in $\mathrm{Ru}(\mathrm{CO})_{2}$ binding (Figure 3 Supporting Information). This finding confirms the tendency of ruthenium-containing molecules to form adducts with His residues and to interact with binding sites close to Asp and Arg residues as previously reported by others. $^{40,42,43}$ The identification of the second amino acid residue involved in the formation of the di-adduct was not possible because the di-modification of the peptide drastically impacts the ionization efficiency and significantly reduces signal intensity. The same phenomenon is also the cause of not detecting the tri-modified peptide. However, as the modifications occur at 6-16 peptide containing three histidine residues and according to the data reported in literature, ${ }^{43}$ it is quite reasonable to assume that the second and the third modification involve $H$ is 13 and 14.

2.3. Inhibition of $A \beta_{1-42}$ Aggregation by CORM-3. After assessing the capacity of CORMs to form stable adduct with $\mathrm{A} \beta_{1-42}$, their anti-aggregation capacity was evaluated. We have previously developed a reproducible $\mathrm{A} \beta_{1-42}$ aggregation protocol, which allows the characterization of different assembly species and a definition of their morphology, molecular weight, and relative abundance. ${ }^{14}$ This information is crucial to avoid confusing outcomes from both aggregation studies and screening of inhibitors. Based on this multimethodological approach, ${ }^{73}$ the effects of CORM-3 on $\mathrm{A} \beta_{1-42}$ aggregation was monitored by different methodologies. ESIMS was applied for the quantification of monomers; CD spectroscopy was used to obtain information on the secondary structure, ${ }^{74,76}$ and a ThT fluorescence assay was applied to assess fibrils formation. ${ }^{84}$ The use of different techniques 
allows for a more comprehensive analysis of increasingly complex interactions involved in prefibrillar species formation during the aggregation process. ${ }^{85}$ Indeed, it was established that $\mathrm{A} \beta$ toxicity is related to specific intermediates. ${ }^{81}$ In this study, we employed the previously proposed multi-methodological approach to follow the $\mathrm{A} \beta_{1-42}$ aggregation process over time in the presence and in the absence of CORM-3 at different concentrations, using myricetin as the reference inhibitor.

2.4. ESI-MS Analysis. ESI-MS has been previously used to highlight the noncovalent interaction of myricetin and other inhibitors with the native peptide. ${ }^{72,73,75,76}$ Using this approach, it was possible to characterize the inhibitors, determining their potency $\left(\mathrm{IC}_{50}\right)$ and their capacity to maintain the $\mathrm{A} \beta_{1-42}$ in its nonamyloidogenic, soluble monomeric form. In the present study, our aim was to verify whether $\mathrm{A} \beta_{1-42} / \mathrm{CORMs}$ interaction could favor the stabilization of the nonamyloidogenic soluble form. Hence, an ESI-MSbased approach was exploited for monitoring the decrease of A $\beta_{1-42}$ soluble monomers along with the mono-, di-, and tri$\mathrm{Ru}(\mathrm{CO})_{2}$-modified monomers formation. In detail, $\mathrm{A} \beta_{1-42}$ (50 $\mu \mathrm{M})$ solution was incubated in the presence and in the absence of $50 \mu \mathrm{M}$ myricetin, $50 \mu \mathrm{M}$ CORM-3, and $250 \mu \mathrm{M}$ CORM-3. At selected times, samples were analyzed by ESI-MS upon addition of reserpine $(30 \mu \mathrm{M})$ as an internal standard. In a time course experiment, the aggregation was followed by monitoring the ratio between the sum of all $[\mathrm{M}+4 \mathrm{H}]^{4+}$ monomer species (native, mono, di-, and tri- $\mathrm{Ru}(\mathrm{CO})_{2^{-}}$ modified) and the internal standard $\left(I_{\mathrm{A} \beta} \beta_{1-42}\right.$ monomers $\left./ I_{\mathrm{Is}}\right)$. The charge state 4 was selected as it is endowed with the highest intensity. As a result of the aggregation process, the signal of the $\mathrm{A} \beta_{1-42}$ monomer progressively decreases until it almost disappears in $48 \mathrm{~h}$, when incubated alone (Ctrl sample, Figure 5). Conversely and in agreement with previous reports, ${ }^{75}$

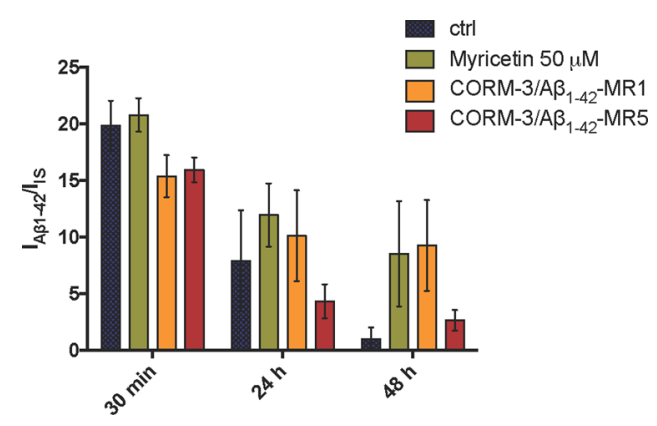

Figure 5. Time-dependent inhibition of $\mathrm{A} \beta_{1-42}$ aggregation. $I_{\mathrm{A} \beta_{1-42} \text { monomers }} / I_{\mathrm{Is}}$ values after $30 \mathrm{~min}, 24$ and $48 \mathrm{~h}$ incubation. $\mathrm{A} \beta_{1-42}$ was incubated in the absence (ctrl) and in the presence of myricetin $(50 \mu \mathrm{M})$, CORM-3 $(50 \mu \mathrm{M})$, and CORM-3 $(250 \mu \mathrm{M})$.

myricetin was able to partially prevent monomer inclusion into higher assemblies, slowing down the aggregation process. Interestingly, CORM-3 was also able to interfere with amyloid aggregation (Figure 5).

It is noteworthy that the inhibitory activity of CORM-3 is higher at lower concentrations (1:1 molar ratio). This effect is further elucidated in Figure 6, where the $\mathrm{A} \beta_{1-42}$ relative abundance in the presence of CORM-3 at 5:1 and $1: 1$ ratio is shown in the time course experiment. The $\mathrm{A} \beta_{1-42}$ in its native form is not detectable after $24 \mathrm{~h}$, when incubated in the presence of CORM-3 at higher concentration. In contrast, at

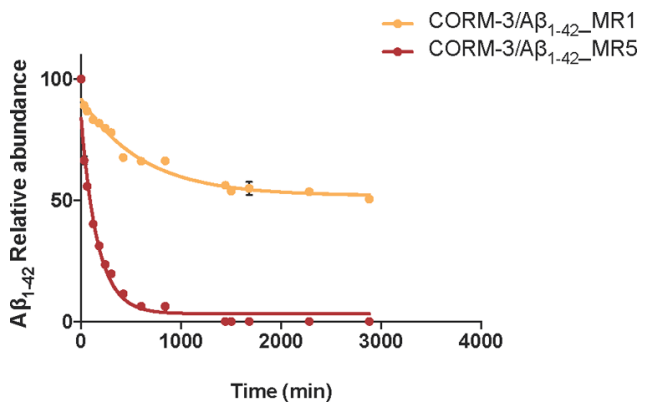

Figure 6. Time-dependent disappearance of $\mathrm{A} \beta_{1-42}$ monomer in the presence of CORM-3. Relative abundance of native $\mathrm{A} \beta_{1-42}$ monomer measured after incubation with CORM-3 at 50 and $250 \mu \mathrm{M}$ is reported ranging from $30 \mathrm{~min}$ to $48 \mathrm{~h}$.

1:1 molar ratio, CORM-3 seems to have an increased stabilizing effect on the $\mathrm{A} \beta_{1-42}$ peptide in its soluble form, as its signal is still detectable after $48 \mathrm{~h}$. To make outcomes trustable, considering the intrinsic variability of an aggregation process, data were collected in duplicate from two independent experiments carried out with different batches of the $\mathrm{A} \beta_{1-42}$ peptide. Future work could look to exploit this chemical insight into biological settings to address the physiological relevance of our observations. This could look to exploit human pluripotent stem cells to maximize the translation aspects ${ }^{86}$ and additional in vivo use of transgenic rodent models ${ }^{87}$ could look to provide insight into CORMs effects on amyloidogenesis.

2.5. ThT Fluorescent Analysis. The selectivity of ThT binding for $\beta$-sheet structures suggests that this assay can prove the ability of compounds to interfere with fibril formation. ${ }^{84}$ $\mathrm{A} \beta_{1-42}(50 \mu \mathrm{M})$ samples were incubated at room temperature with different amounts of CORM-3 to achieve final CORM-3/ $\mathrm{A} \beta_{1-42}$ MRs of $0.5,1.0$, and 5.0. After $48 \mathrm{~h}$ incubation, the samples were diluted with glycine- $\mathrm{NaOH}$ buffer $(50 \mathrm{mM}, \mathrm{pH}$ 8.5) containing $\mathrm{ThT}(1.5 \mu \mathrm{M})$. Fluorescence emission intensity was monitored at $490 \mathrm{~nm}\left(\lambda_{\text {exc }}=446 \mathrm{~nm}\right)$ for 300 s. Fluorescence intensities (IF) at $300 \mathrm{~s}$ were averaged after subtracting the background fluorescence of $1.5 \mu \mathrm{M}$ ThT solution and of the tested compound. Inhibition of fibril formation is expressed as the percent decrease of fluorescence in comparison with the $\mathrm{A} \beta_{1-42}$ control sample. As shown in Figure 7, CORM-3 at $25 \mu \mathrm{M}$ strongly inhibited the formation of $\mathrm{A} \beta_{1-42}$ fibrils to an extent similar to that by myricetin but at

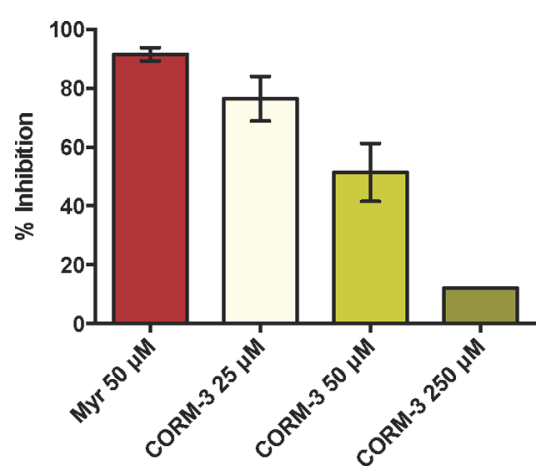

Figure 7. Inhibition of $\mathrm{A} \beta_{1-42}$ aggregation by ThT fluorescence assay. Inhibition of fibrils formation obtained in the presence of myricetin $50 \mu \mathrm{M}$ or CORM-3 at different concentrations is expressed as percentage of fluorescence signal recorded in the presence and in the absence of the inhibitor. 

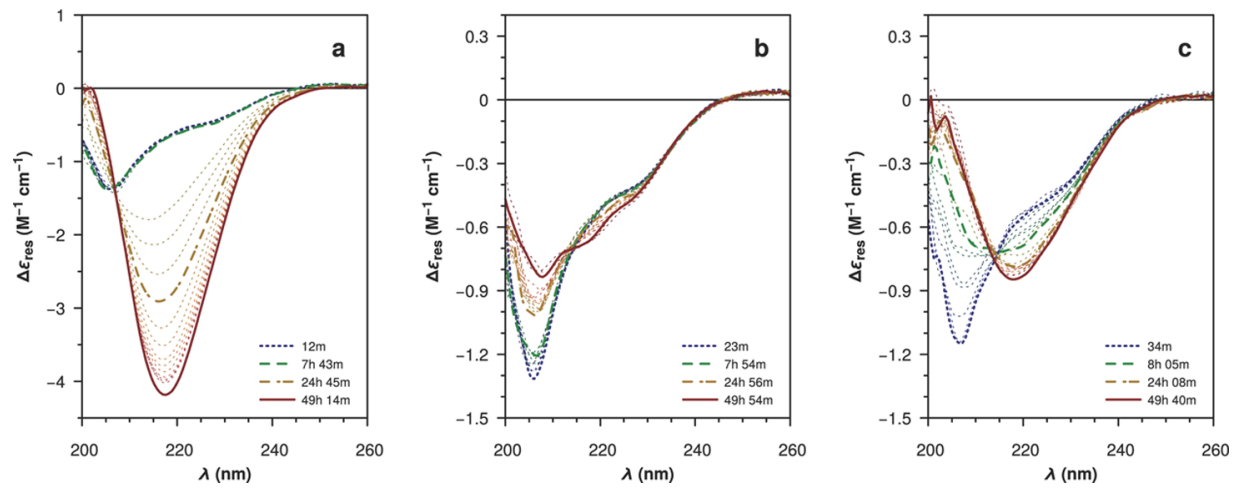

Figure 8. $\mathrm{CD}$ spectra of $\mathrm{A} \beta_{1-42}$ samples at different times after sample preparation. (a) $\mathrm{A} \beta_{1-42}$ in the absence of $\mathrm{CORM}-3$. (b) $\mathrm{A} \beta_{1-42}$ in the presence of CORM-3 at 1:1 molar ratio. (c) $\mathrm{A} \beta_{1-42}$ in the presence of excess CORM-3 at 5:1 molar ratio.

a 2 times lower concentration. In agreement with the MS data (Figure 5), the inhibitory effect was more pronounced at the lowest CORM-3 concentration (lower IF values) at which the extent of $\mathrm{A} \beta$ modification by CORM-3 is lower. This could be explained considering that different degrees of modification could lead to different effects on amyloid aggregation.

2.6. CD Analysis. Misfolding of $\mathrm{A} \beta_{1-42}$ is widely recognized as the earliest step of amyloid aggregation. In order to evaluate the inhibitory effect of CORM-3 on the formation of amyloid aggregates, the change of the $\mathrm{A} \beta_{1-42}$ secondary structure was monitored over $50 \mathrm{~h}$ by $C D$ spectroscopy $^{74}$ (Figures 8 and 9). The CD spectra of $\mathrm{A} \beta_{1-42}$

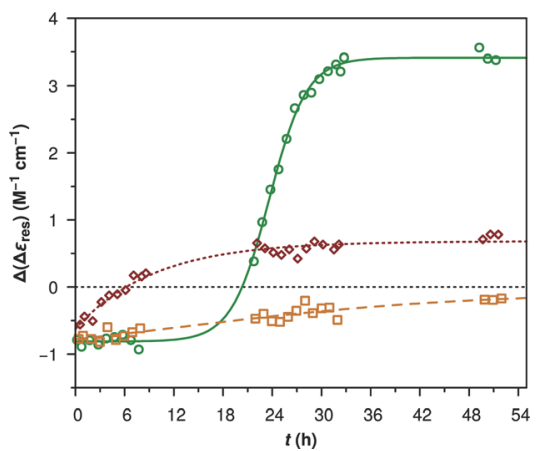

Figure 9. Kinetics of $\mathrm{A} \beta_{1-42}$ misfolding as monitored by $\mathrm{CD}$ spectroscopy. Samples: $\mathrm{A} \beta_{1-42}$ in the absence of CORM-3 (circles, solid line); $\mathrm{A} \beta_{1-42}$ in the presence of CORM-3 at 1:1 molar ratio (squares, dashed line). $\mathrm{A} \beta_{1-42}$ in the presence of excess CORM-3 at 5:1 molar ratio (diamonds, dotted line).

(Figure 8) show a clear transition from a prevalently unordered conformation, characterized by two weak negative bands at around 205 and $230 \mathrm{~nm}$, to a $\beta$-strand structure, characterized by a stronger negative band centered at $218 \mathrm{~nm}$. Based on this observation, the conformational change was monitored using the difference between the CD signals at $205 \mathrm{~nm}$ (unordered) and $218 \mathrm{~nm}$ ( $\beta$-strand) as a function of time (Figure 9). Under the used experimental conditions, the misfolding of $\mathrm{A} \beta_{1-42}$ is complete in $48 \mathrm{~h}$, with the mid-transition point occurring at $23.6 \mathrm{~h}$.

CORM-3 strongly interferes with the $\mathrm{A} \beta_{1-42}$ folding process. The CD spectra of the $\mathrm{A} \beta_{1-42} / \mathrm{CORM}-3$ mixture at $1: 1$ molar ratio (Figure $8 \mathrm{~b}$ ) show a perturbation of the electronic properties of the peptide due to the formation of stable adducts between CORM-3 and a single histidine residue of $\mathrm{A} \beta_{1-42}$. The spectroscopic signature of $\beta$-strand structures, however, was not observed throughout the considered time frame, indicating that the conformational change was fully inhibited (Figure 9). On the other hand, the formation of double and triple $\mathrm{A} \beta_{1-42} / \mathrm{CORM}-3$ adducts in the presence of a 5:1 molar excess of CORM-3 (Figure 8c) induced a conformational change of $\mathrm{A} \beta_{1-42}$ toward a $\beta$-strand-like arrangement which, nevertheless, did not evolve into an extensive amount of misfolded peptide (Figure 9). This interpretation of $\mathrm{CD}$ data is supported by the relative abundance of $\mathrm{A} \beta_{1-42} / \mathrm{CORM}-3$ adducts at different times, as shown by the ESI-MS analysis and by the ThT fluorescence assay. Together, this suggests that the inhibition of amyloid aggregation is highest when the interaction of CORM-3 with $\mathrm{A} \beta_{1-42}$ involves a single histidine residue. The results obtained via $\mathrm{A} \beta_{1-42}$ tryptic digestion confirmed the hypothesis that His6 is the first to be involved by CORM modification.

\section{METHODS}

3.1. Materials. 1,1,1,3,3,3-Hexafluoro-2-propanol, dimethyl sulfoxide (DMSO), methanol, and acetonitrile $\left(\mathrm{CH}_{3} \mathrm{CN}\right)$ (Chromasolv) were obtained from Sigma-Aldrich (Milan, Italy). To prepare buffer solutions, potassium dihydrogen phosphate, dipotassium hydrogen phosphate trihydrate, glycine, sodium carbonate, sodium hydroxide, and sodium chloride (Sigma-Aldrich, Milan, Italy) of analysis quality were used. Human $\mathrm{A} \beta_{1-42}$ lyophilized powder was purchased from Bachem (AG, Switzerland). Reserpine, myricetin (Myr), CORM-3 and CORM-2, trypsin, and ThT were obtained from Sigma-Aldrich (Milan, Italy). Purified water from MilliRX system (Millipore, Milford, MA) was used to prepare buffers and standard solutions. Nitrocellulose $(0.22 \mu \mathrm{m})$ and nylon $(0.20 \mu \mathrm{m})$ membrane filters (Millipore, Carrigtwohill, Ireland B.V.) were employed to filter buffers and solutions. CORM-3 and CORM-2 stock solutions were obtained by dissolving the compounds in water or DMSO, respectively, in order to get the $100 \mathrm{mM}$ starting concentration. Myricetin was solubilized in DMSO at a stock concentration of $1 \mathrm{mg} / \mathrm{mL}$. All compounds were from Sigma-Aldrich (Milan, Italy).

3.2. $A \boldsymbol{\beta}_{1-42}$ Preparation. Following the previously published procedure, ${ }^{73,74} 1 \mathrm{mg}$ of $\mathrm{A} \beta_{1-42}$ lyophilized powder was pretreated overnight with $1400 \mu \mathrm{L}$ of HFIP, portioned, and stored at $-20{ }^{\circ} \mathrm{C}$ after solvent evaporation.

3.3. Characterization of $\mathbf{A} \boldsymbol{\beta}_{1-42}$-CORMs Adducts. An $\mathrm{A} \beta_{1-42}$ aliquot (corresponding to $0.0368 \mu \mathrm{mol}$ ) was solubilized in $69.5 \mu \mathrm{L}$ of a freshly prepared mixture consisting of $\mathrm{CH}_{3} \mathrm{CN} /$ $300 \mu \mathrm{M} \mathrm{Na} \mathrm{CO}_{3} / 250 \mathrm{mM} \mathrm{NaOH}(48.3 / 48.3 / 3.4, \mathrm{v} / \mathrm{v} / \mathrm{v})$ to obtain a $500 \mu \mathrm{M}$ stock solution. CORM-2 $100 \mathrm{mM}$ stock 
solution was prepared in DMSO, whereas the CORM-3 100 $\mathrm{mM}$ stock solution was prepared in water. Stock solutions of the CORMs were kept at $-20{ }^{\circ} \mathrm{C}$ before use.

To study the formation of stable adducts between $\mathrm{A} \beta_{1-42}$ and CORM molecules, $3 \mu \mathrm{L}$ of the $\mathrm{A} \beta_{1-42}$ stock solution was diluted with $27 \mu \mathrm{L}$ of $10 \mathrm{mM}$ phosphate buffer $\mathrm{pH} 7.7$ containing $11 \mathrm{mM} \mathrm{NaCl}$, in the absence and in the presence of CORM-2 or CORM-3 at 5.50, 13.7, 27.5, 55.0, 110, 275, and $550 \mu \mathrm{M}$ concentrations to achieve final CORM/A $\beta_{1-42} \mathrm{MR}$ equal to $0.0,0.1,0.25,0.5,1.0,2.0,5.0$, and 10 , respectively. Samples were incubated at $30^{\circ} \mathrm{C}$ for $3 \mathrm{~h}$ and finally diluted $1: 1$ with water before the LC-MS analysis. Experiments were performed in duplicate.

3.4. Inhibition Studies. 3.4.1. MS-Based Assay. A $\beta_{1-42}$ stock solution was diluted 1:10 with $10 \mathrm{mM}$ phosphate buffer $\mathrm{pH} 7.7$ containing $\mathrm{NaCl} 11 \mathrm{mM}$, in the absence and in the presence of CORM-3 at 55.0 and $275 \mu \mathrm{M}$ concentrations (to achieve the final CORM-3/A $\beta_{1-42}$ MR equals to $0.0,1.0$, and 5.0 , respectively) and in the presence of $55.5 \mu \mathrm{M}$ Myr (final $\mathrm{Myr} / \mathrm{A} \beta_{1-42}$ MR 1: 1$)$. Samples were incubated at room temperature (RT) and, at selected times, $10 \mu \mathrm{L}$ were diluted $1: 1$ with reserpine solution $(30 \mu \mathrm{M}$ in water $/ \mathrm{MeOH}, 50 / 50$, v/ v) employed as the internal standard. The analysis was performed by the LC-MS analysis as reported in Section 2.5. Two independent experiments, each performed in duplicate, were carried out using two different batches of $\mathrm{A} \beta_{1-42}$.

3.4.2. ThT-Based Fluorometric Assay. A $\beta_{1-42}$ stock solution was diluted 1:10 with $10 \mathrm{mM}$ phosphate buffer $\mathrm{pH} 7.7$ containing $11 \mathrm{mM} \mathrm{NaCl}$, in the absence or presence of CORM-3 at 27.5, 55.0, and $275 \mu \mathrm{M}$ concentration to achieve the final CORM-3/A $\beta_{1-42}$ MR equal to $0.0,0.5,1.0$, and 5.0, respectively. Samples were incubated at RT for $48 \mathrm{~h}$ and finally diluted with the glycine- $\mathrm{NaOH}$ buffer (50 mM, pH 8.5) containing ThT $(1.5 \mu \mathrm{M})$ to achieve the final volume of 2.0 $\mathrm{mL}$. Fluorescence emission was monitored by a Jasco FP-6200 spectrofluorometer (Jasco, Tokyo, Japan) using a $3 \mathrm{~mL}$ quartz cell. For each sample, the fluorescence emission signal was monitored at $490 \mathrm{~nm}\left(\lambda_{\text {ex }}=446 \mathrm{~nm}\right)$ with excitation and emission slits of $2 \mathrm{~nm}$ bandwidth. A time scan was performed, and the fluorescence intensity values at the plateau (300 s) were averaged after subtracting the background fluorescence from $1.5 \mu \mathrm{M}$ ThT.

3.4.3. LC-MS Analysis. LC-MS analyses were performed by an Agilent 1200 Series (Walbronn, Germany) coupled with an ESI-Q-ToF mass spectrometer equipped with a Z-spray ion source (Micromass, Manchester, UK). Flow injection analyses were performed by employing water/acetonitrile/FA (70/30/ $0.1 ; \mathrm{v} / \mathrm{v} / \mathrm{v})$ as the mobile phase at the flow rate of $0.1 \mathrm{~mL} / \mathrm{min}$. The injection volume was $5 \mu \mathrm{L}$. The capillary voltage was set at $3000 \mathrm{~V}$, the cone voltage was $40 \mathrm{~V}$, the capillary temperature was $100{ }^{\circ} \mathrm{C}$, while the desolvation temperature was $300{ }^{\circ} \mathrm{C}$. Mass spectra were recorded in total ion current (TIC), within 1000 and $2000 \mathrm{~m} / z$, in positive polarity. The $\mathrm{A} \beta_{1-42}$ baselinesubtracted spectrum $(m / z$ 1100-1700) was deconvoluted onto a true mass scale using the maximum entropy (MaxEnt1)-based software supplied with MassLynx software. The output parameters were mass range: 4100-5200 Da and resolution: $2 \mathrm{Da} /$ channel. The uniform Gaussian model was used, with $0.63 \mathrm{Da}$ width at half height. The $\mathrm{A} \beta_{1-42}$ (alone or forming a complex with CORMs) relative abundance was calculated by dividing the corresponding form intensity by the sum of all forms intensities and multiplying them by 100. Data were analyzed by Excel.
3.4.4. LC-ESI-MS/MS Analysis. A $3 \mu \mathrm{L}$ aliquot of $\mathrm{A} \beta_{1-42}$ stock solution $(500 \mu \mathrm{M})$ was diluted ten folds with $10 \mathrm{mM}$ phosphate buffer $\mathrm{pH} 7.7$ containing $11 \mathrm{mM} \mathrm{NaCl}$, in the absence and in the presence of CORM-2 or CORM-3 to achieve final CORM/A $\beta_{1-42}$ MR equal to 5.0 and 10. Samples were incubated for $3 \mathrm{~h}$ at $30^{\circ} \mathrm{C}$, then $1 \mu \mathrm{L}$ of trypsin $(1 \mu \mathrm{g} /$ $\mu \mathrm{L}$; Sigma T1426) was added and samples were incubated overnight at $37{ }^{\circ} \mathrm{C}$ to allow peptide digestion. $\mathrm{A} \beta_{1-42}$ tryptic digest $(10 \mu \mathrm{L})$, corresponding to 485 pmol, was analyzed by using an Agilent 1100 Series system (Walbronn, Germany). Analyses were performed on a C18 column (Aeris peptide XBC18; $150 \times 2.1 \mathrm{~mm} ; 3.5 \mu \mathrm{m}$; Phenomenex). Mobile phases A [water/acetonitrile/FA (99/1/0.1, v/v/v)] and B [water/ acetonitrile/FA $(1 / 99 / 0.1, \mathrm{v} / \mathrm{v} / \mathrm{v})]$ were used to develop a gradient. The solvent gradient was set as follows: $\mathrm{A}-\mathrm{B}$ from $(98: 8, \mathrm{v} / \mathrm{v})$ to $(40: 60, \mathrm{v} / \mathrm{v})$ in $20 \mathrm{~min} ;(40: 60, \mathrm{v} / \mathrm{v})$ for $2 \mathrm{~min}$. The column was equilibrated with the mobile phase composition of the starting conditions for $10 \mathrm{~min}$ before the next injection. MS analysis was performed on the Q-ToF Micro hybrid analyzer (Micromass, Manchester, UK) with a Zspray ion source. The ESI-Q-ToF source temperature was set at $100{ }^{\circ} \mathrm{C}$, the capillary voltage at $3.0 \mathrm{kV}$, and the cone voltage at $35 \mathrm{~V}$. Peptide ions within a $\mathrm{m} / z 400-1700$ survey scan mass range were analyzed for subsequent fragmentation. $2^{+}, 3^{+}$, and $4^{+}$charged ions exceeding a threshold abundance (TIC value: 10 counts/s) were selected for MS/MS analyses. From a single survey scan, 4 ions were selected for subsequent fragmentation. Scan returns to mass survey mode when the ion intensity falls below 5 counts/s or after $8 \mathrm{~s}$. Scan time was $1 \mathrm{~s}$ for the parent ion and $1 \mathrm{~s}$ for the MS/MS ions. The collision energy was selected using charge state recognition.

3.4.5. CD Analysis. CD measurements were carried out at $25{ }^{\circ} \mathrm{C}$ in the $260-200 \mathrm{~nm}$ spectral range on a Jasco (Tokyo, Japan) J-810 spectropolarimeter equipped with a PTC-423S Peltier-type temperature control system, using QS quartz cells (Hellma Italia, Milan, Italy) with a $0.1 \mathrm{~cm}$ path length, a $2 \mathrm{~nm}$ spectral bandwidth, a $0.5 \mathrm{~nm}$ data interval, a $20 \mathrm{~nm} \mathrm{~min} \mathrm{~min}^{-1}$ scanning speed, and a $2 \mathrm{~s}$ data integration time. $\mathrm{A} \beta_{1-42}$ samples (50 $\mu \mathrm{M}, 200 \mu \mathrm{L}$ final volume), either in the absence or in the presence of CORM-3 at both 1 and $5 \mathrm{MR}$, were prepared as previously described. The CD spectra of all samples were measured at different times after preparation (up to $52 \mathrm{~h}$ ) to follow the time evolution of the secondary structure of $\mathrm{A} \beta_{1-42}$ and evaluate the effect of CORM-3 on the misfolding process. Baseline correction was performed by subtracting the spectral contribution of phosphate buffer $(8.7 \mathrm{mM})$ containing $\mathrm{NaCl}$ (10 mM), $\mathrm{Na}_{2} \mathrm{CO}_{3}(14.5 \mathrm{mM}), \mathrm{NaOH}(0.85 \mathrm{mM})$, and acetonitrile $(8.2 \%, \mathrm{v} / \mathrm{v})$; CORM-3 was not included in the blank solution, as it shows no $\mathrm{CD}$ signal in the spectral range considered in the analysis. Solvent-corrected CD spectra were then converted to molar units per residue $\left(\Delta \varepsilon_{\text {res }}, \mathrm{M}^{-1} \mathrm{~cm}^{-1}\right)$ and plotted using the Bezier smoothing algorithm provided by the Gnuplot software (version 5.2.2, http://gnuplot. sourceforge.net). The conformational change of $\mathrm{A} \beta_{1-42}$ was monitored by plotting the difference between the unsmoothed $\mathrm{CD}$ signals at 205 and $218 \mathrm{~nm}\left(\Delta \varepsilon_{\text {res,205 }}-\Delta \varepsilon_{\text {res,218 }}\right)$ as a function of time.

\section{CONCLUSIONS}

The applied multi-methodological approach provides a detailed analysis of the in vitro $\mathrm{A} \beta_{1-42}$ kinetics by detailing the formation of diverse assembly species. Combination of ThT assay, ESI-MS analysis, and CD studies grant reliable 
information on the overall fibrilization process as well as the identification of aggregation inhibitors and the nature of this inhibition (CD or ESI-MS).

Specifically, the ESI-MS data demonstrated that CORM-3 and CORM-2 directly interact with $\mathrm{A} \beta_{1-42}$, producing stable soluble adducts. This likely occurs through histidine modification via the addition of the $\mathrm{Ru}(\mathrm{CO})_{2}$ moiety. Indeed, the results obtained by the tryptic digestion experiment confirmed the hypothesis that His6 is the first His residue to be involved in $\mathrm{A} \beta$ modification by studied CORMs.

By varying the molar ratio, incubation time and type of CORM, the extent of $\mathrm{A} \beta_{1-42}$ modification changed. CORM-2, possessing two $\mathrm{Ru}$ atoms per molecule, was effective in modifying $\mathrm{A} \beta_{1-42}$ at a lower molar ratio than CORM-3. The higher reactivity highlighted for CORM-2 is certainly due to the different stoichiometry of the beta amyloid: metal reaction. For CORM-2, this rate is twice that for CORM-3. Moreover, Kumar and co-workers reported a much higher binding affinity of the binuclear complex, $\left[(\text { bpy })_{2} \mathrm{Ru}^{2+}(\mathrm{dpp}) \mathrm{Pt}^{2+} \mathrm{Cl}_{2}\right]^{2+}$ instead of the mononuclear $\left[(\mathrm{dpp}) \mathrm{Pt}^{2+} \mathrm{Cl}_{2}\right]$ toward $\mathrm{A} \beta .^{51}$ The results revealed the mono histidine-modified $\mathrm{A} \beta_{1-42}$ to be more soluble and less prone to aggregate than the double- or triplemodified $\mathrm{A} \beta_{1-42}$, implying that the higher stabilizing effect is reached at lower $\mathrm{A} \beta_{1-42} / \mathrm{CORM}-3$ molar ratio. $\mathrm{CD}$ studies highlighted that, in the mono-modified form, the $\beta$-strand conformational change is fully inhibited. On the other hand, the formation of double and triple $\mathrm{A} \beta_{1-42} / \mathrm{CORM}-3$ adducts in the presence of a 1:5 molar excess of CORM-3 induces a conformational change of $\mathrm{A} \beta_{1-42}$ toward a $\beta$-strand-like arrangement which, nevertheless, does not evolve into an extensive misfolding of the peptide. This interpretation of $\mathrm{CD}$ data is supported by the relative abundance of $\mathrm{A} \beta_{1-42} / \mathrm{CORM}$ 3 adducts at different times, as observed by ESI-MS analysis, and by a ThT fluorescence assay, suggesting that the inhibition of amyloid aggregation is the highest when the interaction of CORM-3 with $\mathrm{A} \beta_{1-42}$ involves a single histidine residue.

Therefore, a novel mechanism of action of the CORMs was determined with reference to their capacity to create some stable adducts with $\mathrm{A} \beta_{1-42}$ amino acidic chain.

CORM-3 emerged as a promising inhibitory agent toward $\mathrm{A} \beta_{1-42}$ aggregation. MS and ThT studies also supported the identification of the optimal CORM-3/A $\beta_{1-42}$ ratio for the best inhibitory effect.

This study contributes to the evaluation of the spectrum of activities exerted by CORM-3. In terms of therapeutic potential, the highlighted antiaggregating properties nicely complement the already known neuroprotective and antiinflammatory properties of CORM- $3{ }^{25,26,88,89}$ Therefore, we can use these findings as a further potential mechanism explaining the CORMs-mediated reduction of $\mathrm{A} \beta$ toxicity previously reported in vitro and additionally in vivo. Furthermore, the fact that CORM-3 does not increase CO levels in vivo ${ }^{90}$ and that the $\mathrm{CO}$ trapped by hemoglobin in therapeutic conditions is below the toxicity threshold (in humans, this threshold is close to $10 \% \mathrm{COHb})^{91}$ make these molecules appealing for further developments.

Taken together, the outcomes of this study open up new avenues to explore the potential of CORMs to inhibit aggregation of other disease-related peptides, such as alpha synuclein. ${ }^{92}$

\section{ASSOCIATED CONTENT}

\section{(S) Supporting Information}

The Supporting Information is available free of charge on the ACS Publications website at DOI: 10.1021/acsomega.9b01531.

Method and results for the identification of $\mathrm{A} \beta_{1-42}$ amino acids involved in the formation of stable adducts with CORM-3 and CORM-2 and overlaid time course fluorescence signals obtained for $\mathrm{A} \beta_{1-42}$ samples in thioflavin T-based fluorometric assay (PDF)

\section{AUTHOR INFORMATION}

\section{Corresponding Author}

*E-mail: Vincenza.andrisano@unibo.it.

\section{ORCID}

Andrea Milelli: 0000-0003-2285-7403

Vincenza Andrisano: 0000-0003-4396-1904

Notes

The authors declare no competing financial interest.

\section{ACKNOWLEDGMENTS}

This work was funded in part through an Alzheimer's Association Research Grant to MD (AARG-16-440031). V.A. is grateful for financial support from the University of Bologna (RFO funds).

\section{ABBREVIATIONS}

$\mathrm{A} \beta \quad$ amyloid peptides

$\mathrm{AD} \quad$ Alzheimer's disease

CORMs carbon monoxide releasing molecules

CD circular dichroism

ThT thioflavin $\mathrm{T}$

HO-1 heme oxygenase-1

MS mass spectrometry

ESI electrospray ionization

MR molar ratio

Myr myricetin

\section{REFERENCES}

(1) Aguzzi, A.; O'Connor, T. Protein aggregation diseases: pathogenicity and therapeutic perspectives. Nat. Rev. Drug Discovery 2010, 9, 237-248.

(2) Knowles, T. P. J.; Vendruscolo, M.; Dobson, C. M. The amyloid state and its association with protein misfolding diseases. Nat. Rev. Mol. Cell Biol. 2014, 15, 384-396.

(3) Hardy, J.; Higgins, G. Alzheimer's disease: the amyloid cascade hypothesis. Science 1992, 256, 184-185.

(4) Hardy, J.; Bogdanovic, N.; Winblad, B.; Portelius, E.; Andreasen, N.; Cedazo-Minguez, A.; Zetterberg, H. Pathways to Alzheimer's disease. J. Intern. Med. 2014, 275, 296-303.

(5) Yankner, B. A.; Lu, T. Amyloid beta-protein toxicity and the pathogenesis of Alzheimer disease. J. Biol. Chem. 2009, 284, 47554759.

(6) Pike, C. J.; Walencewicz, A. J.; Glabe, C. G.; Cotman, C. W. Aggregation-related toxicity of synthetic beta-amyloid protein in hippocampal cultures. Eur. J. Pharmacol. Mol. Pharmacol. 1991, 207, 367-368.

(7) Iversen, L. L.; Mortishire-Smith, R. J.; Pollack, S. J.; Shearman, M. S. The toxicity in vitro of beta-amyloid protein. Biochem. J. 1995, $311,1-16$.

(8) Loo, D. T.; Copani, A.; Pike, C. J.; Whittemore, E. R.; Walencewicz, A. J.; Cotman, C. W. Apoptosis is induced by beta- 
amyloid in cultured central nervous system neurons. Proc. Natl. Acad. Sci. U.S.A. 1993, 90, 7951-7955.

(9) White, J. A.; Manelli, A. M.; Holmberg, K. H.; Van Eldik, L. J.; Ladu, M. J. Differential effects of oligomeric and fibrillar amyloid-beta 1-42 on astrocyte-mediated inflammation. Neurobiol. Dis. 2005, 18, $459-465$.

(10) Citron, M. Alzheimer's disease: strategies for disease modification. Nat. Rev. Drug Discovery 2010, 9, 387-398.

(11) Mathur, R.; Ince, P. G.; Minett, T.; Garwood, C. J.; Shaw, P. J.; Matthews, F. E.; Brayne, C.; Simpson, J. E.; Wharton, S. B. A reduced astrocyte response to $\beta$-amyloid plaques in the ageing brain associates with cognitive impairment. PLoS One 2015, 10, e0118463.

(12) Doens, D.; Fernández, P. L. Microglia receptors and their implications in the response to amyloid $\beta$ for Alzheimer's disease pathogenesis. J. Neuroinflammation 2014, 11, 48 .

(13) Garwood, C. J.; Pooler, A. M.; Atherton, J.; Hanger, D. P.; Noble, W. Astrocytes are important mediators of $\mathrm{A} \beta$-induced neurotoxicity and tau phosphorylation in primary culture. Cell Death Dis. 2011, 2, e167.

(14) Verkhratsky, A.; Rodríguez-Arellano, J. J.; Parpura, V.; Zorec, R. Astroglial calcium signalling in Alzheimer's disease. Biochem. Biophys. Res. Commun. 2017, 483, 1005-1012.

(15) Rodríguez-Arellano, J. J.; Parpura, V.; Zorec, R.; Verkhratsky, A. Astrocytes in physiological aging and Alzheimer's disease. Neuroscience 2016, 323, 170-182.

(16) Yeh, C.-Y.; Vadhwana, B.; Verkhratsky, A.; Rodríguez, J. J. Early astrocytic atrophy in the entorhinal cortex of a triple transgenic animal model of Alzheimer's disease. ASN Neuro 2011, 3, AN20110025.

(17) Weaver, L. K. Clinical practice. Carbon monoxide poisoning. $N$. Engl. J. Med. 2009, 360, 1217-1225.

(18) Chang, K.-H.; Chang, M.-Y.; Muo, C.-H.; Wu, T.-N.; Chen, C.Y.; Kao, C.-H. Increased risk of dementia in patients exposed to nitrogen dioxide and carbon monoxide: a population-based retrospective cohort study. PLoS One 2014, 9, e103078.

(19) Brouard, S.; Otterbein, L. E.; Anrather, J.; Tobiasch, E.; Bach, F. H.; Choi, A. M. K.; Soares, M. P. Carbon monoxide generated by heme oxygenase 1 suppresses endothelial cell apoptosis. J. Exp. Med. 2000, 192, 1015-1026.

(20) Otterbein, L. E.; Bach, F. H.; Alam, J.; Soares, M.; Tao Lu, H.; Wysk, M.; Davis, R. J.; Flavell, R. A.; Choi, A. M. K. Carbon monoxide has anti-inflammatory effects involving the mitogenactivated protein kinase pathway. Nat. Med. 2000, 6, 422-428.

(21) Otterbein, L. E.; Zuckerbraun, B. S.; Haga, M.; Liu, F.; Song, R.; Usheva, A.; Stachulak, C.; Bodyak, N.; Smith, R. N.; Csizmadia, E.; Tyagi, S.; Akamatsu, Y.; Flavell, R. J.; Billiar, T. R.; Tzeng, E.; Bach, F. H.; Choi, A. M. K.; Soares, M. P. Carbon monoxide suppresses arteriosclerotic lesions associated with chronic graft rejection and with balloon injury. Nat. Med. 2003, 9, 183-190.

(22) Hettiarachchi, N.; Dallas, M.; Al-Owais, M.; Griffiths, H.; Hooper, N.; Scragg, J.; Boyle, J.; Peers, C. Heme oxygenase-1 protects against Alzheimer's amyloid- $\beta(1-42)$-induced toxicity via carbon monoxide production'. Cell Death Dis. 2014, 5, e1569.

(23) Hettiarachchi, N. T.; Boyle, J. P.; Dallas, M. L.; Al-Owais, M. M.; Scragg, J. L.; Peers, C. Heme oxygenase-1 derived carbon monoxide suppresses A $\beta$. Cell Death Dis. 2017, 8, e2884.

(24) Ma, T.; Chen, Y.; Vingtdeux, V.; Zhao, H.; Viollet, B.; Marambaud, P.; Klann, E. Inhibition of AMP-activated protein kinase signaling alleviates impairments in hippocampal synaptic plasticity induced by amyloid $\beta$. J. Neurosci. 2014, 34, 12230-12238.

(25) Vieira, H. L. A.; Queiroga, C. S. F.; Alves, P. M. Preconditioning induced by carbon monoxide provides neuronal protection against apoptosis. J. Neurochem. 2008, 107, 375-384.

(26) Kim, H. J.; Joe, Y.; Chen, Y.; Park, G. H.; Kim, U.-H.; Chung, H. T. Carbon monoxide attenuates amyloidogenesis via downregulation of NF- $\kappa \mathrm{B}-$ mediated BACE1 gene expression. Aging Cell 2019, 18, e12864.

(27) Chen, J. Heme oxygenase in neuroprotection: from mechanisms to therapeutic implications. Rev. Neurosci. 2014, 25, 269-280.
(28) Motterlini, R.; Mann, B. E. P. A. Therapeutic delivery of carbon monoxide. EP2135605A2, 2002

(29) Motterlini, R.; Clark, J. E.; Foresti, R.; Sarathchandra, P.; Mann, B. E.; Green, C. J. Carbon monoxide-releasing molecules: characterization of biochemical and vascular activities. Circ. Res. 2002, 90, E17-E24

(30) Nobre, L. S.; Seixas, J. D.; Romao, C. C.; Saraiva, L. M. Antimicrobial action of carbon monoxide-releasing compounds. Antimicrob. Agents Chemother. 2007, 51, 4303-4307.

(31) Desmard, M.; Davidge, K. S.; Bouvet, O.; Morin, D.; Roux, D.; Foresti, R.; Ricard, J. D.; Denamur, E.; Poole, R. K.; Montravers, P.; Motterlini, R.; Boczkowski, J. A carbon monoxide-releasing molecule (CORM-3) exerts bactericidal activity against Pseudomonas aeruginosa and improves survival in an animal model of bacteraemia. FASEB J. 2009, 23, 1023-1031.

(32) Vadori, M.; Seveso, M.; Besenzon, F.; Bosio, E.; Tognato, E.; Fante, F.; Boldrin, M.; Gavasso, S.; Ravarotto, L.; Mann, B. E.; Simioni, P.; Ancona, E.; Motterlini, R.; Cozzi, E. In vitro and in vivo effects of the carbon monoxide-releasing molecule, CORM-3, in the xenogeneic pig-to-primate context. Xenotransplantation 2009, 16, 99114.

(33) Wang, G.; Hamid, T.; Keith, R. J.; Zhou, G.; Partridge, C. R.; Xiang, X.; Kingery, J. R.; Lewis, R. K.; Li, Q.; Rokosh, D. G.; Ford, R.; Spinale, F. G.; Riggs, D. W.; Srivastava, S.; Bhatnagar, A.; Bolli, R.; Prabhu, S. D. Cardioprotective and antiapoptotic effects of heme oxygenase-1 in the failing heart. Circulation 2010, 121, 1912-1925.

(34) Johnson, T. R.; Mann, B. E.; Teasdale, I. P.; Adams, H.; Foresti, R.; Green, C. J.; Motterlini, R. Metal carbonyls as pharmaceuticals? $[\mathrm{Ru}(\mathrm{CO}) 3 \mathrm{Cl}($ glycinate $)]$, a CO-releasing molecule with an extensive aqueous solution chemistry. Dalton Trans. 2007, 15, 1500-1508.

(35) Santos-Silva, T.; Mukhopadhyay, A.; Seixas, J. D.; Bernardes, G. J. L.; Romão, C. C.; Romão, M. J. CORM-3 reactivity toward proteins: the crystal structure of a $\mathrm{Ru}(\mathrm{II})$ dicarbonyl-lysozyme complex. J. Am. Chem. Soc. 2011, 133, 1192-1195.

(36) Clark, J. E.; Naughton, P.; Shurey, S.; Green, C. J.; Johnson, T. R.; Mann, B. E.; Foresti, R.; Motterlini, R. Cardioprotective actions by a water-soluble carbon monoxide-releasing molecule. Circ. Res. 2003, 93, e2-8.

(37) Motterlini, R.; Mann, B.; Johnson, T.; Clark, J.; Foresti, R.; Green, C. Bioactivity and pharmacological actions of carbon monoxide-releasing molecules. Curr. Pharm. Des. 2003, 9, 25252539.

(38) Santos-Silva, T.; Mukhopadhyay, A.; Seixas, J.; Bernardes, G.; Romao, C.; Romao, M. Towards improved therapeutic CORMs: understanding the reactivity of CORM-3 with proteins. Curr. Med. Chem. 2011, 18, 3361-3366.

(39) Petruk, A. A.; Vergara, A.; Marasco, D.; Bikiel, D.; Doctorovich, F.; Estrin, D. A.; Merlino, A. Interaction between proteins and Ir based $\mathrm{CO}$ releasing molecules: mechanism of adduct formation and CO release. Inorg. Chem. 2014, 53, 10456-10462.

(40) Pontillo, N.; Ferraro, G.; Messori, L.; Tamasi, G.; Merlino, A. $\mathrm{Ru}$-Based CO releasing molecules with azole ligands: interaction with proteins and the $\mathrm{CO}$ release mechanism disclosed by X-ray crystallography. Dalton Trans. 2017, 46, 9621-9629.

(41) Kapetanaki, S. M.; Burton, M. J.; Basran, J.; Uragami, C.; Moody, P. C. E.; Mitcheson, J. S.; Schmid, R.; Davies, N. W.; Dorlet, P.; Vos, M. H.; Storey, N. M.; Raven, E. A mechanism for CO regulation of ion channels. Nat. Commun. 2018, 9, 907.

(42) Santos, M. F. A.; Seixas, J. D.; Coelho, A. C.; Mukhopadhyay, A.; Reis, P. M.; Romão, M. J.; Romão, C. C.; Santos-Silva, T. New insights into the chemistry of fac- $\left[\mathrm{Ru}(\mathrm{CO})_{3}\right]^{2+}$ fragments in biologically relevant conditions: the $\mathrm{CO}$ releasing activity of $\left[\mathrm{Ru}(\mathrm{CO})_{3} \mathrm{Cl}_{2}(1,3\right.$-thiazole $\left.)\right]$, and the $\mathrm{X}$-ray crystal structure of its adduct with lysozyme. J. Inorg. Biochem. 2012, 117, 285-291.

(43) Valensin, D.; Anzini, P.; Gaggelli, E.; Gaggelli, N.; Tamasi, G.; Cini, R.; Gabbiani, C.; Michelucci, E.; Messori, L.; Kozlowski, H.; Valensin, G. fac- $\{\mathrm{Ru}(\mathrm{CO})(3)\}(2+)$ selectively targets the histidine residues of the beta-amyloid peptide 1-28. Implications for new 
Alzheimer's disease treatments based on ruthenium complexes. Inorg. Chem. 2010, 49, 4720-4722.

(44) Rosenberg, B.; Van Camp, L.; Krigas, T. Inhibition of Cell division in Escherichia coli by electrolysis products from a platinum electrode. Nature 1965, 205, 698-699.

(45) Wang, X.; Guo, Z. Targeting and delivery of platinum-based anticancer drugs. Chem. Soc. Rev. 2013, 42, 202-224.

(46) Leung, C.-H.; Lin, S.; Zhong, H.-J.; Ma, D.-L. Metal complexes as potential modulators of inflammatory and autoimmune responses. Chem. Sci. 2015, 6, 871-884.

(47) Guo, Z.; Sadler, P. J. Metals in Medicine. Angew. Chem., Int. Ed. 1999, 38, 1512-1531.

(48) Liu, J.; Chakraborty, S.; Hosseinzadeh, P.; Yu, Y.; Tian, S.; Petrik, I.; Bhagi, A.; Lu, Y. Metalloproteins containing cytochrome, iron-sulfur, or copper redox centers. Chem. Rev. 2014, 114, 43664469 .

(49) Messori, L.; Camarri, M.; Ferraro, T.; Gabbiani, C.; Franceschini, D. Promising in Vitro anti-Alzheimer Properties for a Ruthenium(III) Complex. ACS Med. Chem. Lett. 2013, 4, 329-332.

(50) Barnham, K. J.; Kenche, V. B.; Ciccotosto, G. D.; Smith, D. P.; Tew, D. J.; Liu, X.; Perez, K.; Cranston, G. A.; Johanssen, T. J.; Volitakis, I.; Bush, A. I.; Masters, C. L.; White, A. R.; Smith, J. P.; Cherny, R. A.; Cappai, R. Platinum-based inhibitors of amyloid-beta as therapeutic agents for Alzheimer's disease. Proc. Natl. Acad. Sci. U.S.A. 2008, 105, 6813-6818.

(51) Kumar, A.; Moody, L.; Olaivar, J. F.; Lewis, N. A.; Khade, R. L.; Holder, A. A.; Zhang, Y.; Rangachari, V. Inhibition of A $\beta 42$ peptide aggregation by a binuclear ruthenium(II)-platinum(II) complex: Potential for multi-metal organometallics as anti-amyloid agents. ACS Chem. Neurosci. 2010, 1, 691-701.

(52) Bush, A. I. Metal complexing agents as therapies for Alzheimer's disease. Neurobiol. Aging 2002, 23, 1031-1038.

(53) Bush, A. I.; Masters, C. L.; Tanzi, R. E. Copper, beta-amyloid, and Alzheimer's disease: tapping a sensitive connection'. Proc. Natl. Acad. Sci. U.S.A. 2003, 100, 11193-11194.

(54) Bush, A. I. The metallobiology of Alzheimer's Disease. Trends Neurosci. 2003, 26, 207-214.

(55) Lovell, M. A.; Xie, C.; Markesbery, W. R. Protection against amyloid beta peptide toxicity by zinc. Brain Res. 1999, 823, 88-95.

(56) Kepp, K. P. Bioinorganic chemistry of Alzheimer's disease. Chem. Rev. 2012, 112, 5193-5239.

(57) Gaggelli, E.; Kozlowski, H.; Valensin, D.; Valensin, G. Copper homeostasis and neurodegenerative disorders (Alzheimer's, prion, and Parkinson's diseases and amyotrophic lateral sclerosis). Chem. Rev. 2006, 106, 1995-2044.

(58) Atwood, C. S.; Huang, X.; Moir, R. D.; Tanzi, R. E.; Bush, A. I. Role of free radicals and metal ions in the pathogenesis of Alzheimer's disease. Met. Ions Biol. Syst. 1999, 36, 309-364.

(59) Bush, A. I.; Tanzi, R. E. Therapeutics for Alzheimer's disease based on the metal hypothesis. Neurotherapeutics 2008, 5, 421-432.

(60) Huang, X.; Moir, R. D.; Tanzi, R. E.; Bush, A. I.; Rogers, J. T. Redox-active metals, oxidative stress, and Alzheimer's disease pathology. Ann. N. Y. Acad. Sci. 2004, 1012, 153-163.

(61) Faller, P.; Hureau, C. Bioinorganic chemistry of copper and zinc ions coordinated to amyloid-beta peptide. Dalton Trans. 2009, $1080-1094$

(62) Braymer, J. J.; Giedroc, D. P. Recent developments in copper and zinc homeostasis in bacterial pathogens. Curr. Opin. Chem. Biol. 2014, 19, 59-66.

(63) Faller, P. Copper and zinc binding to amyloid-beta: coordination, dynamics, aggregation, reactivity and metal-ion transfer. ChemBioChem 2009, 10, 2837-2845.

(64) Hureau, C.; Balland, V.; Coppel, Y.; Solari, P. L.; Fonda, E.; Faller, P. Importance of dynamical processes in the coordination chemistry and redox conversion of copper amyloid-beta complexes. JBIC, J. Biol. Inorg. Chem. 2009, 14, 995-1000.

(65) Liu, H.; Qu, Y.; Wang, X. Amyloid $\beta$-targeted metal complexes for potential applications in Alzheimer's disease. Future Med. Chem. 2018, 10, 679-701.
(66) Suh, J.-M.; Kim, G.; Kang, J.; Lim, M. H. Strategies Employing Transition Metal Complexes To Modulate Amyloid- $\beta$ Aggregation. Inorg. Chem. 2019, 58, 8-17.

(67) Richter, M. M.; Brewer, K. J. Spectroscopic, electrochemical and spectroelectrochemical investigations of mixed-metal Os(II)/ $\mathrm{Ru}(\mathrm{II})$ bimetallic complexes incorporating polypyridyl bridging ligands. Inorg. Chem. 1992, 31, 1594-1598.

(68) Richter, M. M.; Brewer, K. J. Investiga- tion of the spectroscopic, electrochemical and spectro- electrochemical properties of Os(II) complexes incorporat- ing polyazine bridging ligands: Formation of the $\mathrm{Os}, \mathrm{Os}$ and $\mathrm{Os}, \mathrm{Ru}$ mixed-valence complexes. Inorg. Chem. 1993, 32, 2827-2834.

(69) Richter, M. M.; Brewer, K. J. Osmium/ ruthenium trimetallics incorporating polyazine bridging li- gands: Isovalent NIR absorbers with unique electrochemical behavior. Inorg. Chem. 1993, 32, 57625768.

(70) Klein, W.; Krafft, G. A.; Finch, C. E. Targeting small Abeta oligomers: the solution to an Alzheimer's disease conundrum? Trends Neurosci. 2001, 24, 219-224.

(71) Kokkoni, N.; Stott, K.; Amijee, H.; Mason, J. M.; Doig, A. J. NMethylated peptide inhibitors of beta-amyloid aggregation and toxicity. Optimization of the inhibitor structure. Biochemistry 2006, 45, 9906-9918.

(72) Fiori, J.; Naldi, M.; Andrisano, V. Mass spectrometry as an efficient tool for the characterization of amyloid $\beta$ peptide $25-35$ selfassembly species in aggregation and inhibition studies. Eur. J. Mass Spectrom. 2013, 19, 483-490.

(73) Bartolini, M.; Naldi, M.; Fiori, J.; Valle, F.; Biscarini, F.; Nicolau, D. V.; Andrisano, V. Kinetic characterization of amyloid-beta 1-42 aggregation with a multimethodological approach. Anal. Biochem. 2011, 414, 215-225.

(74) Bartolini, M.; Bertucci, C.; Bolognesi, M. L.; Cavalli, A.; Melchiorre, C.; Andrisano, V. Insight into the kinetic of amyloid beta (1-42) peptide self-aggregation: elucidation of inhibitors' mechanism of action. ChemBioChem 2007, 8, 2152-2161.

(75) Fiori, J.; Naldi, M.; Bartolini, M.; Andrisano, V. Disclosure of a fundamental clue for the elucidation of the myricetin mechanism of action as amyloid aggregation inhibitor by mass spectrometry. Electrophoresis 2012, 33, 3380-3386.

(76) Naldi, M.; Fiori, J.; Pistolozzi, M.; Drake, A. F.; Bertucci, C.; Wu, R.; Mlynarczyk, K.; Filipek, S.; De Simone, A.; Andrisano, V. Amyloid $\beta$-peptide $25-35$ self-assembly and its inhibition: a model undecapeptide system to gain atomistic and secondary structure details of the Alzheimer's disease process and treatment. ACS Chem. Neurosci. 2012, 3, 952-962.

(77) Beck, J.; Humphries, A.; Sheil, M.; Ralph, S. Electrospray Ionisation Mass Spectrometry of Ruthenium and Palladium Complexes with Oligonucleotides. Eur. J. Mass Spectrom. 1999, 5, 489.

(78) Kang, J.; Lee, S. J. C.; Nam, J. S.; Lee, H. J.; Kang, M.-G.; Korshavn, K. J.; Kim, H.-T.; Cho, J.; Ramamoorthy, A.; Rhee, H.-W.; Kwon, T.-H.; Lim, M. H. An Iridium(III) Complex as a Photoactivatable Tool for Oxidation of Amyloidogenic Peptides with Subsequent Modulation of Peptide Aggregation. Chem.-Eur. J. 2017, 23, $1645-1653$

(79) He, L.; Wang, X.; Zhu, D.; Zhao, C.; Du, W. Methionine oxidation of amyloid peptides by peroxovanadium complexes: inhibition of fibril formation through a distinct mechanism. Metallomics 2015, 7, 1562-1572.

(80) Heffern, M. C.; Velasco, P. T.; Matosziuk, L. M.; Coomes, J. L.; Karras, C.; Ratner, M. A.; Klein, W. L.; Eckermann, A. L.; Meade, T. J. Modulation of amyloid- $\beta$ aggregation by histidine-coordinating Cobalt(III) Schiff base complexes. ChemBioChem 2014, 15, 15841589.

(81) Sakono, M.; Zako, T. Amyloid oligomers: formation and toxicity of Abeta oligomers. FEBS J. 2010, 277, 1348-1358.

(82) Findeis, M. A. Approaches to discovery and characterization of inhibitors of amyloid beta-peptide polymerization. Biochim. Biophys. Acta, Mol. Basis Dis. 2000, 1502, 76-84. 
(83) Hong, J.; Miao, Y.; Miao, R.; Yang, G.; Tang, H.; Guo, Z.; Zhu, L. Binding sites of $[\mathrm{Ru}(\mathrm{bpy}) 2(\mathrm{H} 2 \mathrm{O}) 2](\mathrm{BF} 4) 2$ with sulfur- and histidine-containing peptides studied by electrospray ionization mass spectrometry and tandem mass spectrometry. J. Mass Spectrom. 2005, 40, 91-99.

(84) LeVine, H. [18] Quantification of $\beta$-sheet amyloid fibril structures with thioflavin T. Methods Enzymol. 1999, 309, 274-284.

(85) Sengupta, U.; Nilson, A. N.; Kayed, R. The Role of Amyloid- $\beta$ Oligomers in Toxicity, Propagation, and Immunotherapy. EBioMedicine 2016, 6, 42-49.

(86) Csöbönyeiová, M.; Polák, Š.; Danišovič, L. Recent approaches and challenges in iPSCs: modeling and cell-based therapy of Alzheimer's disease. Rev. Neurosci. 2016, 27, 457-464.

(87) Mucke, L.; Masliah, E.; Yu, G.-Q.; Mallory, M.; Rockenstein, E. M.; Tatsuno, G.; Hu, K.; Kholodenko, D.; Johnson-Wood, K.; McConlogue, L. High-level neuronal expression of abeta 1-42 in wildtype human amyloid protein precursor transgenic mice: synaptotoxicity without plaque formation. J. Neurosci. 2000, 20, 4050-4058.

(88) Kim, H. J.; Joe, Y.; Chen, Y.; Park, G. H.; Kim, U.-H.; Chung, H. T. Carbon monoxide attenuates amyloidogenesis via downregulation of NF- $\kappa \mathrm{B}$-mediated BACE1 gene expression. Aging Cell 2018, 18, e12864.

(89) Motterlini, R.; Haas, B.; Foresti, R. Emerging concepts on the anti-inflammatory actions of carbon monoxide-releasing molecules (CO-RMs). Med. Gas Res. 2012, 2, 28.

(90) Motterlini, R.; Otterbein, L. E. The therapeutic potential of carbon monoxide. Nat. Rev. Drug Discovery 2010, 9, 728-743.

(91) Romão, C. C.; Blättler, W. A.; Seixas, J. D.; Bernardes, G. J. L. Developing drug molecules for therapy with carbon monoxide. Chem. Soc. Rev. 2012, 41, 3571-3583.

(92) Pujols, J.; Peña-Díaz, S.; Lázaro, D. F.; Peccati, F.; Pinheiro, F.; González, D.; Carija, A.; Navarro, S.; Conde-Giménez, M.; García, J.; Guardiola, S.; Giralt, E.; Salvatella, X.; Sancho, J.; Sodupe, M.; Outeiro, T. F.; Dalfó, E.; Ventura, S. Small molecule inhibits $\alpha$ synuclein aggregation, disrupts amyloid fibrils, and prevents degeneration of dopaminergic neurons. Proc. Natl. Acad. Sci. U.S.A. 2018, 115, 10481-10486. 